\begin{tabular}{|c|c|}
\hline 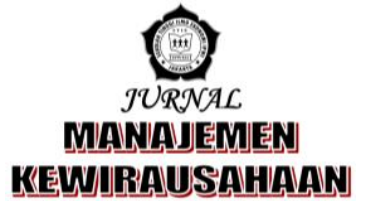 & $\begin{array}{r}\text { p-ISSN 1858-1048 } \\
\text { e-ISSN 2654-9247 } \\
\text { http://ejurnal.stieipwija.ac.id/index.php/jmk } \\
\text { DOI: http://dx.doi.org/10.33370/jmk.v16i2.333 } \\
\text { Jurnal Manajemen Kewirausahaan Vol. 16 No. 02 - Desember } 2019 \\
\text { Submit: 12 Nov 2019; Review: 03 Des 2019; Publish: 31 Des } 2019\end{array}$ \\
\hline
\end{tabular}

\title{
PENGARUH KUALITAS PELAYANAN DAN HARGA TERHADAP KEPUASAN PELANGGAN PADA PIZZA HUT DELIVERY CABANG CILEUNGSI
}

\author{
Oleh: \\ Risko Ramadan'), Rasipan'), Joni Heruwanto ${ }^{3)}$ \\ riskobombom@gmail.com ${ }^{1}$, ipan081267@yahoo.com ${ }^{2}$, joniheruwanto@yahoo.com ${ }^{3)}$ \\ Sekolah Tinggi Ilmu Ekonomi IPWI Jakarta1,2,3)
}

\begin{abstract}
ABSTRAK
Tujuan penelitian untuk mengetahui kualitas pelayanan dan harga yang diberikan oleh Pizza Hut Delivery cabang Cileungsi serta untuk mengetahui kepuasan pelanggan Pizza Hut Delivery cabang Cileungsi.

Metode yang digunakan dalam penelitian ini adalah metode kuantitatif hal ini dimaksudkan untuk menghitung dari angket data kualitas pelayanan dan harga sebagai variabel bebas atau X1 dan X2 yang sudah diketahui dan menghitung angket data kepuasan pelanggan. Hasil analisa regresi dapat dibuat persamaan regresi berganda.

Penelitian menghasilkan dua temuan utama sesuai dengan hipotesis yang akan diajukan yaitu kualitas pelayanan memiliki pengaruh positif terhadap kepuasan pelanggan lalu harga memiliki pengaruh positif terhadap kepuasan pelanggan.

Berdasarkan temuan tersebut maka untuk meningkatkan kepuasan pelanggan disarankan agar dilakukan upaya memperbaiki kualitas pelayanan dan meninjau harga.
\end{abstract}

Kata Kunci: kualitas pelayanan, harga, kepuasan pelanggan

\section{PENDAHULUAN}

Perkembangan dan peningkatan jasa pelayanan pada restoran fastfood dari tahun ke tahun semakin menjadi perhatian masyarakat, Hal ini dapat dilihat dari ketatnya persaingan dalam hal kualitas produk, harga, promosi, dan distribusi dari sekian banyaknya restoran yang ada di Indonesia.Persaingan yang ketat menyebabkan suatu restoran perlu melakukan usaha pelayanan terbaik kepada konsumenya, Hal ini menyebabkan restoran - restoran yang ada saling berlomba untuk menyediakan kemudahan dan kelengkapan produk yang sesuai dengan keinginan konsumen untuk tercapainya kepuasan pelanggan.Dari sekian banyak restoran waralaba yang berkembang di Indonesia salah satunya adalah Restoran Pizza Hut Delivery.

Beberapa keluhan dari pelanggan yang merasa kurang puas dengan Pizza Hut Delivery cabang Cileungsi, Persaingan antara perusahaan penghasil produk makanan cepat saji saat ini juga sangat kompetitif.Dari tingkat pembelian konsumen, guna mempertahankan jumlah pengunjung yang datang, maka pihak Pizza Hut Delivery Cileungsi hendaknya berusaha untuk 
menciptakan kesadaran merek kepada pelanggan bahwa Pizza Hut Delivery adalah merek kelas internasional yang selalu menjaga kualitas dengan melalui promosi, disamping itu pihak restoran juga memberikan keragaman menu dan kualitas pelayanan yang disajikan.

\section{TUJUAN PENELITIAN}

Penelitian ini dilakukan dengan tujuan sebagai berikut:

1. Mengetahui kualitas pelayanan dan harga yang diberikan oleh Pizza Hut Delivery cabang Cileungsi.

2. Mengetahui kepuasan pelanggan Pizza Hut Delivery cabang Cileungsi

\section{TELAAH LITERATUR DAN \\ PENGEMBANGAN \\ PROPOSISI/HIPOTESIS \\ Manajemen Pemasaran}

Manajemen pemasaran adalah proses penetapan tujuan-tujuan pemasaran suatu organisasi (dengan mempertimbangkan sumber daya internal dan peluang pasar) perencanaan, dan pelaksanaan aktivitas untuk memenuhi tujuan-tujuan tersebut dan mengukur kemajuan ke arah pencapaiannya.

\section{Kualitas Pelayanan}

Menurut Vincent Gaspersz (2011:7) kualitas didefinisikan sebagai totalitas dari karakteristik suatu produk yang menunjang kemampuannya untuk memuaskan kebutuhan yang dispesifikasikan atau ditetapkan. kualitas seringkali diartikan sebagai kepuasan pelanggan (customer satisfaction) atau kesesuaian terhadap kebutuhan atau persyaratan (conformance to the requirements).

Menurut Kotler (2013:83) pengertian pelayanan yaitu "setiap tindakan atau kegiatan yang dapat ditawarkan oleh satu pihak kepada pihak lain pada dasarnya tidak berwujud dan tidak mengakibatkan kepemilikan apapun".

\section{Harga}

Menurut Philip Kotler, harga adalah elemen pemasaran campuran yang paling mudah untuk mengatur keistimewaan produk. Harga juga mengkomunikasikan pada pasar penempatan nilai produk atau merek yang dimaksud suatu perusahaan.

\section{Faktor yang mempengaruhi Harga}

1. Harga bahan baku

2. Biaya produksi

3. Biaya pemasaran

4. Peraturan pemerintah

\section{Kepuasan Pelanggan}

Kepuasan pelanggan merupakan respon pelanggan terhadap ketidaksesuaian antara tingkat kepentingan sebelumnya dan kinerja aktual yang dirasakannya setelah pemakaian.

Menurut Kotler yang dikutip kembali oleh Fandy Tjiptono dkk (2012:312) mengemukakan bahwa kepuasan konsumen adalah tingkat perasaan seseorang setelah membandingkan kinerja atau hasil yang ia persepsikan dibandingkan dengan harapannya.

\section{Kerangka Pemikiran \\ Hipotesis 1}

H1: terdapat pengaruh kualitas pelayanan terhadap kepuasan pelanggan pada Pizza Hut Delivery Cabang Cileungsi.

\section{Hipotesis 2}

H2: terdapat pengaruh harga terhadap kepuasan pelanggan pada Pizza Hut Delivery Cabang Cileungsi.

Gambar 1

Kerangka/Konstelasi

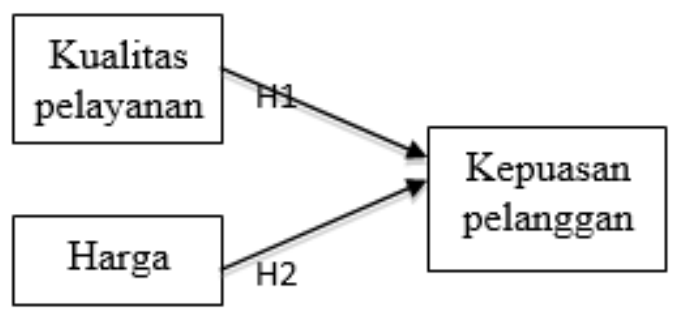

\section{METODE PENELITIAN}

Jenis penelitian yang digunakan dalam penelitian ini adalah explanatory research tipe kausal yang berupaya menguji pengaruh variable independen 
terhadap variable dependen. Lingkup penelitian ini adalah menguji pengaruh kualitas pelayanan dan harga terhadap kepuasan pelanggan pada Pizza Hut Delivery.

\section{Sampel Penelitian}

Berdasarkan penelitian maka penulis mengambil $100 \%$ jumlah populasi yang ada yaitu sebanyak 100 orang responden.

\section{Desain Penelitian}

Terdapat 3 variabel penelitian yaitu, 2 variabel independen dan satu variabel dependen. Variabel independen yang pertama yaitu kualitas pelayanan dengan simbol $\mathrm{X} 1$ dan variabel independen kedua yaitu Harga dengan simbol X2. Satu variabel dependen yaitu kepuasan pelanggan dengan simbol Y.

\section{Operasionalisasi Variabel}

Operasionalisasi variabel penelitian dapat dikemukakan sebagai berikut:

Tabel 1

Operasional Variabel Penelitian

\begin{tabular}{|c|c|c|c|}
\hline Variabel & Indikator & Skala & Item Pertanyaan \\
\hline $\begin{array}{l}\text { Kualitas pelayanan (X1) } \\
\text { adalah Kotler (2008:83) } \\
\text { pengertian pelayanan yaitu } \\
\text { "setiap tindakan atau } \\
\text { kegiatan yang dapat } \\
\text { ditawarkan oleh satu pihak } \\
\text { kepada pihak lain pada } \\
\text { dasarnya tidak berwujud } \\
\text { dan tidak mengakibatkan } \\
\text { kepemilikan apapun" } \\
\end{array}$ & $\begin{array}{ll}\text { 1. Bukti langsung } \\
\text { 2. Keandalan } \\
\text { 3. Daya tanggap } \\
\text { 4. Jaminan } \\
\text { 5. Empati }\end{array}$ & $\begin{array}{c}\text { Interval } \\
1-5\end{array}$ & $\begin{array}{ll}\text { 1. } & \text { Sangat Tidak Setuju } \\
\text { 2. } & \text { Tidak Setuju } \\
\text { 3. } & \text { Netral } \\
\text { 4. } & \text { Setuju } \\
\text { 5. } & \text { Sangat Setuju }\end{array}$ \\
\hline $\begin{array}{l}\text { Harga (X2) adalah } \\
\text { elemen pemasaran } \\
\text { campuran yang paling } \\
\text { mudah untuk mengatur } \\
\text { lkeistimewaan } \\
\text { produk.perusahaan ('Philip } \\
\text { Kotler, et. al, Manajemen } \\
\text { Pemasaran 2013) }\end{array}$ & $\begin{array}{ll}\text { 1. } & \text { Harga jual } \\
\text { 2. } & \text { Kesesuaian } \\
\text { harga } \\
\text { 3. } & \text { Perbandingan } \\
\text { harga } \\
\text { 4. Harga } \\
\text { berpariasi } \\
\text { 5. Harga } \\
\text { terjangkau }\end{array}$ & $\begin{array}{c}\text { Interval } \\
1-5\end{array}$ & $\begin{array}{l}\text { 1. Sangat Tidak Setuju } \\
\text { 2. Tidak Setuju } \\
\text { 3. Netral } \\
\text { 4. Setuju } \\
\text { 5. Sangat Setuju }\end{array}$ \\
\hline $\begin{array}{l}\text { Kepuasan pelanggan (Y) } \\
\text { adalah perasaan senang } \\
\text { atau kecewa seseorang } \\
\text { yang timbul karena } \\
\text { membandingkan kinerja } \\
\text { yang telah dipersepsikan } \\
\text { produk (atau hasil) terhadap } \\
\text { ekspektasi mereka" Kotler } \\
\text { dan Keller (2009:138) }\end{array}$ & 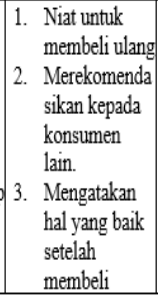 & $\begin{array}{c}\text { Interval } \\
1-5\end{array}$ & $\begin{array}{ll}\text { 1. } & \text { Sangat Tidak Setuju } \\
\text { 2. } & \text { Tidak Setuju } \\
\text { 3. } & \text { Netral } \\
\text { 4. } & \text { Setuju } \\
\text { 5. } & \text { Sangat Setuju }\end{array}$ \\
\hline
\end{tabular}

\section{Instrumen Penelitian}

Analisis data menggunakan software SPSS dengan empat tahap. Pertama, pengujian kualitas data. Tahap kedua, melakukan uji penyimpangan asumsi klasik. Tahap ketiga, melakukan analisis regresi berganda. Dan tahap keempat, melakukan pengujian hipotesis.

\section{Metode Analisis Data Uji Validitas}

Sebuah instrumen dikatakan valid apabila instrumen itu mampu mengukur apa yang diinginkan dan dapat mengukur data dari variabel yang diteliti secara tepat.

\section{Uji Reliabilitas}

Reliabilitas menunjukkan pada suatu pengertian bahwa suatu instrumen cukup dapat dipercaya untuk digunakan sebagai alat pengumpul data karena instrumen tersebut sudah baik (Arikunto, 2012:154). Instrumen yang sudah dapat dipercaya, yang reliabel akan menghasilkan data yang dapat dipercaya juga.

\section{Uji Asumsi Klasik}

Uji asumsi klasik terdiri dari uji normalitas, linieritas, multikolinieritas, autokorelasi, dan heteroskedastisitas, yang dapat dijelaskan sebagai berikut (Mulyanto dan Wulandari, 2010:181).

\section{Analisis Regresi Berganda}

Analisis ini digunakan untuk menunjukkan pengaruh variabel bebas terhadap variabel terikat.

\section{HASIL DAN PEMBAHASAN Hasil Penelitian}

Hasil uji validitas dan realibilitas masing-masing variabel adalah:

\section{Uji Validitas dan Reliabilitas Variabel Kualitas Pelayanan (X1)}

Variabel kualitas pelayanan diperoleh dari 10 pernyataan yaitu X1.1 sampai dengan X1.10. Validitas variabel kualitas pelayanan diuji dengan membandingkan nilai $r_{\text {hitung }}$ (kolom Correted Item-Total Correlation) hasil Output SPSS dengan nilai $r_{\text {tabel }}$ jika nilai $r>0,196$ maka dianggap valid.

Sedangkan Hasil uji variabel kualitas pelayanan mendapat nilai Cronbach's Alpha lebih besar dari nilai kritis $(0,860>0,60)$ maka variabel kualitas pelayanan dinyatakan reliabel. 


\section{Uji Validitas dan Reliabilitas Variabel Harga (X2)}

Variabel harga diperoleh dari 10 pernyataan yaitu X2.1 sampai dengan X2.10. Validitas variabel harga diuji dengan membandingkan nilai $\mathrm{r}_{\text {hitung }}$ (kolom Correted Item-Total Correlation) hasil output SPSS dengan nilai $r_{\text {tabel }}$ jika nilai $r>0,196$ maka dianggap valid.

Sedangkan Hasil uji variabel harga mendapat nilai Cronbach's Alpha lebih besar dari nilai kritis $(0,873>0,60)$ maka variabel harga dinyatakan reliabel.

\section{Uji Validitas dan Reliabilitas Variabel Kepuasan Pelanggan (Y)}

Variabel kepuasan pelanggan diperoleh dari 10 pernyataan yaitu Y.1 sampai dengan Y.10. Validitas variabel Kepuasan pelanggan diuji dengan membandingkan nilai r $\mathrm{r}_{\text {hitung }}$ (kolom Correted Item-Total Correlation) hasil Output SPSS dengan nilai $r_{\text {tabel }}$ Jika nilai $r \geq 0,196$ maka dianggap valid.

Sedangkan Hasil uji variabel kepuasan pelanggan mendapat nilai Cronbach's Alpha lebih besar dari nilai kritis $(0,>0,60)$ maka variabel kepuasan pelanggan dinyatakan reliabel.

Tabel 2

Hasil Uji Korelasi dan Regresi

Model Summary ${ }^{\mathrm{b}}$

\begin{tabular}{|l|c|c|c|c|c|}
\hline Model & $\mathrm{R}$ & $\mathrm{R}$ Square & $\begin{array}{c}\text { Adjusted R } \\
\text { Square }\end{array}$ & $\begin{array}{c}\text { Std. Error of } \\
\text { the Estimate }\end{array}$ & $\begin{array}{c}\text { Durbin- } \\
\text { Watson }\end{array}$ \\
\hline 1 & $.467^{\mathrm{7}}$ & .218 & .202 & 3.836 & 1.964 \\
\hline
\end{tabular}

a. Predictors: (Constant), HARGA, KUALITAS PELAYANAN

\section{b. Dependent Variable: KEPUASAN PELANGGAN}

Dari tabel model summary di atas maka diperoleh nilai koefisien determinasi ganda (Adjusted $\mathrm{R}$ Square) sebesar 0.202 menunjukkan bahwa X1 Kualitas Pelayanan, X2 Harga Pelayanan dalam model secara bersama-sama mampu menjelaskan $12,8 \%$ sedangkan $87,2 \%$ variasi Y lainnya dijelaskan oleh variabel lain yang tidak diteliti.
Analisis Regresi Berganda

Tabel 3

Hasil Uji Regresi Berganda

Coefficients $^{\mathrm{a}}$

\begin{tabular}{|c|c|c|c|c|c|c|}
\hline \multirow{2}{*}{\multicolumn{2}{|c|}{ Model }} & \multicolumn{2}{|c|}{$\begin{array}{l}\text { Unstandardized } \\
\text { Coefficients }\end{array}$} & \multirow{2}{*}{$\begin{array}{c}\begin{array}{c}\text { Standardized } \\
\text { Coefficients }\end{array} \\
\text { Beta }\end{array}$} & \multirow[b]{2}{*}{$t$} & \multirow[b]{2}{*}{ Sig. } \\
\hline & & B & $\begin{array}{l}\text { Std. } \\
\text { Error }\end{array}$ & & & \\
\hline \multirow[t]{3}{*}{1} & (Constant) & 24.182 & 3.815 & & 6.338 & .000 \\
\hline & $\begin{array}{l}\text { KUALITAS } \\
\text { PELAYANAN }\end{array}$ & .122 & .065 & .171 & 1.881 & .063 \\
\hline & HARGA & .340 & .076 & .407 & 4.475 & .000 \\
\hline
\end{tabular}

a. Dependent Variable: KEPUASAN

PELANGGAN

Dari tabel di atas dapat disusun model persamaan regresi liniear ganda sebagai berikut:

$$
\begin{aligned}
\mathrm{Y}= & 24.182+0.122+0.340 \\
& (0.063)(0.000)
\end{aligned}
$$

Model persamaan regresi linier ganda hasil analisis tersebut dapat diartikan sebagai berikut:

- Nilai konstanta sebesar b $=24.291$, artinya bahwa jika X1 dan X2 dianggap konstan maka $\mathrm{Y}$ akan bernilai positif.

- Nilai koefisien regresi X1 sebesar b1 $=0,122$ menunjukkan bahwa X1 berpengaruh terhadap $\mathrm{Y}$ dengan arah positif.

- Nilai koefisien regresi X2 sebesar b2 $=0,340$ menunjukkan bahwa X2 berpengaruh terhadap $\mathrm{Y}$ dengan arah positif.

\section{Pengujian Hipotesis}

Pengujian hipotesis penelitian ini dilakukan dengan Uji t. Pengujian hipotesis dalam penelitian sebanyak dua kali sesuai dengan hepotesis penelitian.

Uji Hipotesis 1: Pengaruh Kualitas Pelayanan Terhadap Kepuasan pelanggan

Nilai Sig t untuk Kualitas Pelayanan (X1) sebesar b1 $=0$ memiliki nilai probabilitas $t_{\text {hitung }}$ sebesar 1.881 , oleh karena nilai $t_{\text {hitung }} 0,000<0,05$ dan nilai b1 $\neq 0$, maka $\mathrm{H}_{10}$ ditolak dan $\mathrm{H}_{1 \mathrm{a}}$ diterima, dapat dinyatakan bahwa Kualitas Pelayanan (X1) berpengaruh terhadap Kepuasan Pelanggan (Y) dan berpengaruh positif, sehingga dapat dinyatakan bahwa semakin tinggi Kualitas Pelayanan maka semakin tinggi pula Kepuasan Pelanggan. 
Uji Hipotesis 2: Pengaruh Harga terhadap Kepuasan pelanggan.

Nilai Sig t untuk Harga (X2) sebesar $\mathrm{b} 2=0,340$ memiliki nilai probabilitas thitung sebesar 4.473, oleh karena nilai thitung $0,340>0,05$ dan nilai $\mathrm{b} 2 \neq 0$, maka $\mathrm{H} 2 \mathrm{o}$ diterima dan $\mathrm{H} 2 \mathrm{a}$ ditolak, dapat dinyatakan bahwa Harga (X2) berpengaruh terhadap Kepuasan pelanggan dan berpengaruh positif, sehingga dapat dinyatakan bahwa semakin tinggi Harga maka semakin tinggi pula Kepuasan Pelanggan.

\section{Pembahasan \\ Pengaruh Kualitas Pelayanan terhadap Kepuasan Pelanggan}

Penelitian menemukan bahwa

kualitas pelayanan berpengaruh terhadap kepuasan pelanggan. Hal ini berbanding lurus dengan penelitian sebelumnya oleh Eswika Nila sari \& Istiatin yang menyatakan bahwa kualitas pelayanan berpengaruh terhadap kepuasan pelanggan. Pelanggan yang mendapatkan pelayanan yang memuaskan, dalam hal ini kualitas layanan dinilai baik oleh pelanggan, akan berpengaruh terhadap kepuasan pelanggan Pizza Hut Delivery.

\section{Pengaruh Harga terhadap Kepuasan Pelanggan}

Penelitian juga menemukan bahwa harga berpengaruh terhadap kepuasan pelanggan. Hasil penelitian ini sesuai dengan penelitian terdahulu oleh Ani Mustika, Yoyo Indah Gunawan yang menyatakan bahwa harga berpengaruh terhadap kepuasan pelanggan. Harga yang dinilai baik dan terjangkau serta sesuai dengan kualitas produk akan berpengaruh terhadap kepuasan pelanggan Pizza Hut Delivery.

\section{KESIMPULAN}

\section{Simpulan}

1. Kualitas Pelayanan memiliki pengaruh terhadap Kepuasan Pelanggan dengan arah positif sebesar $b 1=0,122$ pada model persamaan regresi linier ganda.

2. Harga memiliki pengaruh terhadap Kepuasan Pelanggan dengan arah yang positif sebesar b2 $=0.340$ pada persamaan regresi linear ganda.

\section{Saran}

Berdasarkan hasil penelitian di temukan beberapa kendala dan masalah dalam penelitian.

1. Berdasarkan hasil analisis penelitian menggunakan metode statistik, sehingga dapat diketahui makna pengaruh antara variabel bebas yaitu Kualitas Pelayanan dan Harga terhadap variabel terikat yaitu Kepuasan Pelanggan di PHD Indonesia cab, Cileungsi.

2. Bagi pihak perusahaan agar menjadi acuan untuk meningkatkan kualitas pelayanan dan harga yang lebih baik lagi agar kepuasan pelanggan akan tetap terjaga.

3. Dengan penelitian yang ada saat ini agar peneliti selanjutnya bisa menambahkan variabel yang lain seperti kualitas produk sehingga akan dapat diperoleh penjelasan yang lebih lengkap mengenai keinginan paling mendasar dari kepuasan pelanggan.

\section{DAFTAR PUSTAKA}

Ghozali, Imam. (2005). Aplikasi Analisis Multivariate dengan SPSS. Semarang: Badan Penerbit UNDIP.

Hurriyati, Ratih. (2010). Bauran Pemasaran dan Loyalitas Konsumen. Jakarta: Alfabeta.

Hermawan, Agus. 2012. Komunikasi Pemasaran. Jakarta: Erlangga.

Kotler, Philip. (2017). Manajemen Pemarasan ed. Rev. jilid 2. Jakarta.

Kotler dan Keller. (2013). Marketing Management Edisi 14, Global Edition. Pearson Prentice Hall.

Kotler, Philip dan Kevin Lane Keller. (2013). Manajemen Pemasaran, Edisi Ketiga Belas, Jilid 1, dialih bahasa kan oleh Benjamin Molan, Jakarta: PT Indeks.

Kotler, Philip dan Kevin Lane Keller. (2013). Manajemen Pemasaran, Edisi Ketiga Belas, Jilid 1, dialihbahasakan oleh Benjamin Molan, Jakarta: PT Indeks. 
Kotler, Philip dan Kevin Lane Keller. (2008). Manajemen Pemasaran

(Edisi Kedua Belas), Cetakan Ketiga. Jakarta: PT. Indeks.

Silalahi, Ulber. (2011). Asas-Asas Manajemen. Bandung: Refika Aditama.

Sugiyono. (2009). Metode Penelitian Kuantitatif, Kualitatif dan $R \& D$. Bandung: Alfabeta.

Suryabrata, Sumadi. (2007). Psikologi Kepribadian. Jakarta: Raja Grafindo Persada.

Wirawan. 2013. Kepemimpinan: Teori, Psikologi, Perilaku Organisasi, Aplikasi dan Penelitian. Jakarta: PT. Raja Grafindo Persada. 